\title{
Generalized Mann Iterations for Approximating Fixed Points of a Family of Hemicontractions
}

\author{
Liang-Gen Hu, ${ }^{1}$ Ti-Jun Xiao, ${ }^{2}$ and Jin Liang ${ }^{3}$ \\ ${ }^{1}$ Department of Mathematics, University of Science and Technology of China, Hefei 230026, China \\ ${ }^{2}$ School of Mathematical Sciences, Fudan University, Shanghai 200433, China \\ ${ }^{3}$ Department of Mathematics, Shanghai Jiaotong University, Shanghai 200240, China
}

Correspondence should be addressed to Jin Liang, jliang@ustc.edu.cn

Received 10 January 2008; Accepted 15 May 2008

Recommended by Hichem Ben-El-Mechaiekh

This paper concerns common fixed points for a finite family of hemicontractions or a finite family of strict pseudocontractions on uniformly convex Banach spaces. By introducing a new iteration process with error term, we obtain sufficient and necessary conditions, as well as sufficient conditions, for the existence of a fixed point. As one will see, we derive these strong convergence theorems in uniformly convex Banach spaces and without any requirement of the compactness on the domain of the mapping. The results given in this paper extend some previous theorems.

Copyright (C) 2008 Liang-Gen Hu et al. This is an open access article distributed under the Creative Commons Attribution License, which permits unrestricted use, distribution, and reproduction in any medium, provided the original work is properly cited.

\section{Introduction}

Let $X$ be a real Banach space and $K$ a nonempty closed subset of $X$. A mapping $T: K \rightarrow K$ is said to be pseudocontractive (see, e.g., [1]) if

$$
\|T x-T y\|^{2} \leq\|x-y\|^{2}+\|(I-T) x-(I-T) y\|^{2}
$$

holds for all $x, y \in K$. T is said to be strictly pseudocontractive if, for all $x, y \in K$, there exists a constant $k \in[0,1)$ such that

$$
\|T x-T y\|^{2} \leq\|x-y\|^{2}+k\|(I-T) x-(I-T) y\|^{2} .
$$

Denote by $\operatorname{Fix}(T)=\{x \in K: T x=x\}$ the set of fixed points of $T$. A map $T: K \rightarrow K$ is called hemicontractive if $\operatorname{Fix}(T) \neq \varnothing$ and for all $x \in K, x^{*} \in \operatorname{Fix}(T)$, the following inequality holds:

$$
\left\|T x-x^{*}\right\|^{2} \leq\left\|x-x^{*}\right\|^{2}+\|x-T x\|^{2} .
$$


It is easy to see that the class of pseudocontractive mappings with fixed points is a subset of the class of hemicontractions.

There are many papers in the literature dealing with the approximation of fixed points for several classes of nonlinear mappings (see, e.g., [1-11], and the reference therein). In these works, there are two iterative methods to be used to find a point in $\operatorname{Fix}(T)$. One is explicit and one is implicit.

The explicit one is the following well-known Mann iteration. defined by

Let $K$ be a nonempty closed convex subset of $X$. For any $x_{0} \in K$, the sequence $\left\{x_{n}\right\}$ is

$$
x_{n+1}=\left(1-\alpha_{n}\right) x_{n}+\alpha_{n} T x_{n}, \quad \forall n \geq 0,
$$

where $\left\{\alpha_{n}\right\}$ is a real sequence in $[0,1]$ satisfying some assumptions.

It has been applied to many classes of nonlinear mappings to find a fixed point. However, for hemicontractive mappings and strictly pseudocontractive mappings, the iteration process of convergence is in general not strong (see a counterexample given by Chidume and Mutangadura [3]). Most recently, Marino and Xu [6] proved that the Mann iterative sequence $\left\{x_{n}\right\}$ converges weakly to a fixed point for strictly pseudocontractive mappings in a Hilbert space, while the real sequence $\left\{\alpha_{n}\right\}$ satisfying (i) $k<\alpha_{n}<1$ and (ii) $\sum_{n=0}^{\infty}\left(\alpha_{n}-k\right)\left(1-\alpha_{n}\right)=+\infty$.

In order to get strong convergence for fixed points of hemicontractive mappings and strictly pseudocontractive mappings, the following Mann-type implicit iteration scheme is introduced.

Let $K$ be a nonempty closed convex subset of $X$ with $K+K \subseteq K$. For any $x_{0} \in K$, the sequence $\left\{x_{n}\right\}$ is generated by

$$
x_{n}=\alpha_{n} x_{n-1}+\left(1-\alpha_{n}\right) T x_{n}, \quad \forall n \geq 1,
$$

where $\left\{\alpha_{n}\right\}$ is a real sequence in $[0,1]$ satisfying suitable conditions.

Recently, in the setting of a Hilbert space, Rafiq [12] proved that the Mann-type implicit iterative sequence $\left\{x_{n}\right\}$ converges strongly to a fixed point for hemicontractive mappings, under the assumption that the domain $K$ of $T$ is a compact convex subset of a Hilbert space, and $\left\{\alpha_{n}\right\} \subset[\delta, 1-\delta]$ for some $\delta \in(0,1)$.

In this paper, we will study the strong convergence of the generalized Mann-type iteration scheme (see Definition 2.1) for hemicontractive and, respectively, pseudocontractive mappings. As we will see, our theorems extend the corresponding results in [12] in four aspects. (1) The space setting is a more general one: uniformly convex Banach space, which could not be a Hilbert space. (2) The requirement of the compactness on the domain of the mapping is dropped. (3) A single mapping is replaced by a family of mappings. (4) The Mann-type implicit iteration is replaced by the generalized Mann iteration. Moreover, we give answers to a question asked in [13].

\section{Preliminaries and lemmas}

Definition 2.1 (generalized Mann iteration). Let $N \geq 1$ be a fixed integer, $\Lambda:=\{1,2, \ldots, N\}$, and $K$ a nonempty closed convex subset of $X$ satisfying the condition $K+K \subseteq K$. Let $\left\{T_{i}: i \in \Lambda\right\}$ : $K \rightarrow K$ be a family of mappings. For each $x_{0} \in K$, the sequence $\left\{x_{n}\right\}$ is defined by

$$
x_{n}=a_{n} x_{n-1}+b_{n} T_{[n]} x_{n}+c_{n} u_{n}, \quad \forall n \geq 1,
$$


where $T_{[n]}=T_{n \bmod N},\left\{a_{n}\right\},\left\{b_{n}\right\}$, and $\left\{c_{n}\right\}$ are three sequences in $[0,1]$ with $a_{n}+b_{n}+c_{n}=1$ and $\left\{u_{n}\right\} \subset K$ is bounded.

The modulus of convexity of $X$ is the function $\delta_{X}:[0,2] \rightarrow[0,1]$ defined by

$$
\delta_{X}(\varepsilon)=\inf \left\{1-\left\|\frac{1}{2}(x+y)\right\|:\|x\|=\|y\|=1,\|x-y\| \geq \varepsilon\right\}, \quad 0 \leq \varepsilon \leq 2 .
$$

$X$ is called uniformly convex if and only if, for all $0<\varepsilon \leq 2$ such that $\delta_{X}(\varepsilon)>0$. X is called $p$-uniformly convex if there exists a constant $a>0$, such that $\delta_{X}(\varepsilon) \geq a \varepsilon^{p}$. It is well known (see [10]) that

$$
L^{p}, l^{p}, W^{1, p} \text { is } \begin{cases}2 \text {-uniformly convex, } & \text { if } 1<p \leq 2 \\ p \text {-uniformly convex, } & \text { if } p \geq 2\end{cases}
$$

Let $X$ be a Banach space, $Y \subset X$, and $x \in X$. Then, we denote $d(x, Y):=\inf _{y \in Y}\|x-y\|$.

Definition 2.2 (see [4]). Let $f:[0,+\infty) \rightarrow[0,+\infty)$ be a nondecreasing function with $f(0)=0$ and $f(r)>0$, for all $r \in(0,+\infty)$.

(i) A mapping $T: K \rightarrow K$ with $\operatorname{Fix}(T) \neq \varnothing$ is said to satisfy condition (A) on $K$ if there is a function $f$ such that for all $x \in K,\|x-T x\| \geq f(d(x, \operatorname{Fix}(T)))$.

(ii) A finite family of mappings $\left\{T_{i}: i \in \Lambda\right\}: K \rightarrow K$ with $F:=\bigcap_{i=1}^{N} \operatorname{Fix}\left(T_{i}\right) \neq \varnothing$ are said to satisfy condition $(\overline{\mathbf{B}})$ if there exists a function $f$, such that $\max _{1 \leq i \leq N}\left\{\left\|x-T_{i} x\right\|\right\} \geq$ $f(d(x, F))$ holds for all $x \in K$.

Lemma 2.3 (see [8]). Let $X$ be a real uniformly convex Banach space with the modulus of convexity of power type $p \geq 2$. Then, for all $x, y$ in $X$ and $\lambda \in(0,1)$, there exists a constant $d_{p}>0$ such that

$$
\|\lambda x+(1-\lambda) y\|^{p} \leq \lambda\|x\|^{p}+(1-\lambda)\|y\|^{p}-w_{p}(\lambda) d_{p}\|x-y\|^{p},
$$

where $w_{p}(\lambda)=\lambda^{p}(1-\lambda)+\lambda(1-\lambda)^{p}$.

Remark 2.4. If $p=2$ in the previous lemma, then we denote $d_{2}:=d$.

Lemma 2.5. Let $X$ be a real Banach space and $J: X \rightarrow 2^{X^{*}}$ the normalized duality mapping. Then for any $x, y$ in $X$ and $j(x+y) \in J(x+y)$, such that

$$
\|x+y\|^{2} \leq\|x\|^{2}+2\langle y, j(x+y)\rangle .
$$

Lemma 2.6 (see [7]). Let $\left\{\alpha_{n}\right\},\left\{\beta_{n}\right\}$, and $\left\{\gamma_{n}\right\}$ be three nonnegative real sequences, satisfying

$$
\alpha_{n+1} \leq\left(1+\beta_{n}\right) \alpha_{n}+\gamma_{n}, \quad \forall n \geq 1,
$$

with $\sum_{n=1}^{\infty} \beta_{n}<+\infty$ and $\sum_{n=1}^{\infty} \gamma_{n}<+\infty$. Then, $\lim _{n \rightarrow \infty} \alpha_{n}$ exists. In addition, if $\left\{\alpha_{n}\right\}$ has a subsequence converging to zero, then $\lim _{n \rightarrow \infty} \alpha_{n}=0$.

Proposition 2.7. If $T$ is a strict pseudocontraction, then $T$ satisfies the Lipschitz condition

$$
\|T x-T y\| \leq \frac{1+\sqrt{k}}{1-\sqrt{k}}\|x-y\|, \quad \forall x, y \in K .
$$


Proof. By the definition of the strict pseudocontraction, we have

$$
\|T x-T y\|^{2} \leq\|x-y\|^{2}+k\|(I-T) x-(I-T) y\|^{2} \leq(\|x-y\|+\sqrt{k}\|(I-T) x-(I-T) y\|)^{2} .
$$

A simple computation shows the conclusion.

\section{Main results}

Lemma 3.1. Let $X$ be a uniformly convex Banach space with the convex modulus of power type $p \geq 2, K$ a nonempty closed convex subset of $X$ satisfying $K+K \subseteq K$, and $\left\{T_{i}: i \in \Lambda\right\}: K \rightarrow K$ hemicontractive mappings with $\bigcap_{i=1}^{N} \operatorname{Fix}\left(T_{i}\right) \neq \varnothing$. Let $\left\{a_{n}\right\},\left\{b_{n}\right\},\left\{c_{n}\right\},\left\{u_{n}\right\}$, and $\left\{x_{n}\right\}$ be the sequences in (II) and

$$
\begin{aligned}
& \text { (i) } \sum_{n=1}^{\infty} c_{n}<+\infty \text {, }
\end{aligned}
$$

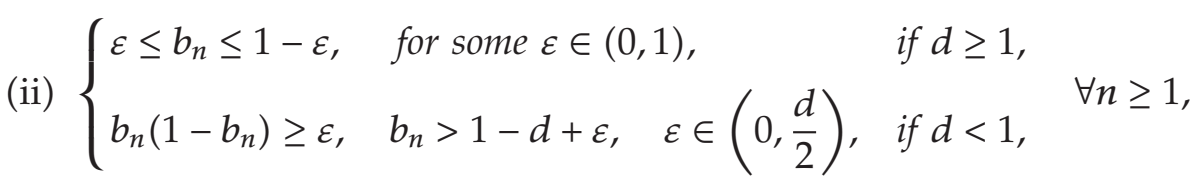

where $d$ is the constant in Remark 2.4. Then,

(1) $\lim _{n \rightarrow \infty}\left\|x_{n}-q\right\|$ exists for all $q \in F:=\bigcap_{i=1}^{N} \operatorname{Fix}\left(T_{i}\right)$,

(2) $\lim _{n \rightarrow \infty} d\left(x_{n}, F\right)$ exists,

(3) if $T_{i}(i \in \Lambda)$ is continuous, then $\lim _{n \rightarrow \infty}\left\|x_{n}-T_{i} x_{n}\right\|=0$, for all $i \in \Lambda$.

Proof. (1) Let $q \in F=\bigcap_{i=1}^{N} \operatorname{Fix}\left(T_{i}\right)$. By the boundedness assumption on $\left\{u_{n}\right\}$, there exists a constant $M>0$, for any $n \geq 1$, such that $\left\|u_{n}-q\right\| \leq M$. From the definition of hemicontractive mappings, we have

$$
\left\|T_{i} x_{n}-q\right\|^{2} \leq\left\|x_{n}-q\right\|^{2}+\left\|x_{n}-T_{i} x_{n}\right\|^{2}, \quad \forall i \in \Lambda .
$$

Using Lemmas 2.3, 2.5, and (3.2), we obtain

$$
\begin{aligned}
\left\|x_{n}-q\right\|^{2}= & \left\|\left(1-b_{n}\right)\left(x_{n-1}-q\right)+b_{n}\left(T_{[n]} x_{n}-q\right)+c_{n}\left(u_{n}-x_{n-1}\right)\right\|^{2} \\
\leq & \left\|\left(1-b_{n}\right)\left(x_{n-1}-q\right)+b_{n}\left(T_{[n]} x_{n}-q\right)\right\|^{2}+2 c_{n}\left\langle u_{n}-x_{n-1}, j\left(x_{n}-q\right)\right\rangle \\
\leq & \left(1-b_{n}\right)\left\|x_{n-1}-q\right\|^{2}+b_{n}\left\|T_{[n]} x_{n}-q\right\|^{2}-b_{n}\left(1-b_{n}\right) d\left\|x_{n-1}-T_{[n]} x_{n}\right\|^{2} \\
& +2 c_{n}\left(\left\|u_{n}-q\right\|+\left\|x_{n-1}-q\right\|\right)\left\|x_{n}-q\right\| \\
\leq & \left(1-b_{n}\right)\left\|x_{n-1}-q\right\|^{2}+b_{n}\left\|x_{n}-q\right\|^{2}+b_{n}\left\|x_{n}-T_{[n]} x_{n}\right\|^{2} \\
& -b_{n}\left(1-b_{n}\right) d\left\|x_{n-1}-T_{[n]} x_{n}\right\|^{2}+2 c_{n} M \\
& +2 c_{n} M\left\|x_{n}-q\right\|^{2}+c_{n}\left\|x_{n-1}-q\right\|^{2}+c_{n}\left\|x_{n}-q\right\|^{2} .
\end{aligned}
$$


Hence,

$$
\begin{aligned}
\left(a_{n}-2 c_{n} M\right)\left\|x_{n}-q\right\|^{2} \leq & \left(a_{n}+2 c_{n}\right)\left\|x_{n-1}-q\right\|^{2}+b_{n}\left\|x_{n}-T_{[n]} x_{n}\right\|^{2} \\
& -b_{n}\left(1-b_{n}\right) d\left\|x_{n-1}-T_{[n]} x_{n}\right\|^{2}+2 c_{n} M .
\end{aligned}
$$

It follows from (II) and Lemma 2.5 that

$$
\begin{aligned}
\left\|x_{n}-T_{[n]} x_{n}\right\|^{2} & =\left\|\left(a_{n}+c_{n}\right)\left(x_{n-1}-T_{[n]} x_{n}\right)+c_{n}\left(u_{n}-x_{n-1}\right)\right\|^{2} \\
& \leq\left(1-b_{n}\right)^{2}\left\|x_{n-1}-T_{[n]} x_{n}\right\|^{2}+2 c_{n}\left\langle u_{n}-x_{n-1}, j\left(x_{n}-T_{[n]} x_{n}\right)\right\rangle \\
& \leq\left(1-b_{n}\right)^{2}\left\|x_{n-1}-T_{[n]} x_{n}\right\|^{2}+2 c_{n} M^{2}+2 c_{n}\left\|x_{n-1}-q\right\|^{2}+c_{n}\left\|x_{n}-T_{[n]} x_{n}\right\|^{2} .
\end{aligned}
$$

By the condition $\sum_{n=1}^{\infty} c_{n}<+\infty$, we may assume that

$$
\frac{1}{1-c_{n}} \leq 1+2 c_{n}, \quad \forall n \geq 1
$$

Therefore,

$$
\left\|x_{n}-T_{[n]} x_{n}\right\|^{2} \leq \frac{\left(1-b_{n}\right)^{2}}{1-c_{n}}\left\|x_{n-1}-T_{[n]} x_{n}\right\|^{2}+2 M^{2} c_{n}\left(1+2 c_{n}\right)+2 c_{n}\left(1+2 c_{n}\right)\left\|x_{n-1}-q\right\|^{2}
$$

Substituting (3.7) into (3.4), we get

$$
\begin{aligned}
\left(a_{n}-2 c_{n} M\right)\left\|x_{n}-q\right\|^{2} \leq & {\left[a_{n}+2 c_{n}+2 b_{n} c_{n}\left(1+2 c_{n}\right)\right]\left\|x_{n-1}-q\right\|^{2}+\frac{b_{n}\left(1-b_{n}\right)^{2}}{1-c_{n}}\left\|x_{n-1}-T_{[n]} x_{n}\right\|^{2} } \\
& -b_{n}\left(1-b_{n}\right) d\left\|x_{n-1}-T_{[n]} x_{n}\right\|^{2}+2 c_{n} M+2 c_{n} b_{n}\left(1+2 c_{n}\right) M^{2} \\
= & {\left[a_{n}+2 c_{n}+2 b_{n} c_{n}\left(1+2 c_{n}\right)\right]\left\|x_{n-1}-q\right\|^{2}-b_{n}\left(1-b_{n}\right)\left(d-\frac{1-b_{n}}{1-c_{n}}\right) } \\
& \times\left\|x_{n-1}-T_{[n]} x_{n}\right\|^{2}+2 c_{n} M+2 c_{n} b_{n}\left(1+2 c_{n}\right) M^{2} .
\end{aligned}
$$

Assumptions (i) and (ii) imply that there exists a positive integer $N_{1}$ such that for every $n>$ $N_{1}$

$$
a_{n}-2 c_{n} M \geq \eta>0, \quad d-\frac{1-b_{n}}{1-c_{n}} \geq \zeta>0
$$

Hence, for all $n>N_{1}$,

$$
\begin{aligned}
\left\|x_{n}-q\right\|^{2} \leq & \left\{1+\frac{2\left[M+1+b_{n}\left(1+2 c_{n}\right)\right] c_{n}}{a_{n}-2 c_{n} M}\right\}\left\|x_{n-1}-q\right\|^{2} \\
& -\frac{b_{n}\left(1-b_{n}\right)}{a_{n}-2 c_{n} M}\left[d-\frac{1-b_{n}}{1-c_{n}}\right]\left\|x_{n-1}-T_{[n]} x_{n}\right\|^{2}+\frac{2 M\left[b_{n}\left(1+2 c_{n}\right) M+1\right] c_{n}}{a_{n}-2 c_{n} M} \\
= & \left(1+\lambda_{n}\right)\left\|x_{n-1}-q\right\|^{2}-\sigma_{n}\left\|x_{n-1}-T_{[n]} x_{n}\right\|^{2}+\delta_{n},
\end{aligned}
$$


where

$$
\begin{aligned}
& \lambda_{n}=2\left[M+1+b_{n}\left(1+2 c_{n}\right)\right] c_{n} \eta^{-1}, \\
& \sigma_{n}=\frac{b_{n}\left(1-b_{n}\right)}{a_{n}-2 c_{n} M}\left[d-\frac{1-b_{n}}{1-c_{n}}\right], \\
& \delta_{n}=2 M\left[b_{n}\left(1+2 c_{n}\right) M+1\right] c_{n} \eta^{-1} .
\end{aligned}
$$

From (3.9) and conditions (i) and (ii), it follows that

$$
\sum_{n=1}^{\infty} \lambda_{n}<+\infty, \quad \sum_{n=1}^{\infty} \delta_{n}<+\infty, \quad \sigma_{n} \geq \sigma>0 .
$$

By Lemma 2.6, we see that $\lim _{n \rightarrow+\infty}\left\|x_{n}-q\right\|$ exists and the sequence $\left\{\left\|x_{n}-q\right\|\right\}$ is bounded.

(2) It is easy to verify that $\lim _{n \rightarrow \infty} d\left(x_{n}, F\right)$ exists.

(3) By the boundedness of $\left\{\left\|x_{n}-q\right\|\right\}$, there exists a constant $M_{1}>0$ such that $\left\|x_{n}-q\right\| \leq$ $M_{1}$, for all $n \geq 1$. From (3.10), we get, for $n>N_{1}$,

$$
\sigma\left\|x_{n-1}-T_{[n]} x_{n}\right\|^{2} \leq\left\|x_{n-1}-q\right\|^{2}-\left\|x_{n}-q\right\|^{2}+\lambda_{n} M_{1}+\delta_{n}
$$

which implies

$$
\sigma \sum_{n=N_{1}}^{\infty}\left\|x_{n-1}-T_{[n]} x_{n}\right\|^{2} \leq \sum_{n=N_{1}}^{\infty}\left(\left\|x_{n-1}-q\right\|^{2}-\left\|x_{n}-q\right\|^{2}\right)+\sum_{n=N_{1}}^{\infty}\left(\lambda_{n} M_{1}+\delta_{n}\right)<+\infty .
$$

Thus,

$$
\sum_{n=1}^{\infty}\left\|x_{n-1}-T_{[n]} x_{n}\right\|^{2}<+\infty
$$

It implies that

$$
\lim _{n \rightarrow \infty}\left\|x_{n-1}-T_{[n]} x_{n}\right\|=0
$$

Therefore, by (3.7), we have

$$
\lim _{n \rightarrow \infty}\left\|x_{n}-T_{[n]} x_{n}\right\|=0
$$

Using (II), we obtain

$$
\begin{gathered}
\left\|x_{n}-x_{n-1}\right\| \leq \frac{b_{n}}{a_{n}}\left\|x_{n-1}-T_{[n]} x_{n}\right\|+\frac{c_{n}}{a_{n}}\left\|u_{n}-x_{n-1}\right\| \longrightarrow 0, \quad n \longrightarrow \infty, \\
\left\|x_{n+i}-x_{n}\right\| \longrightarrow 0, \quad n \longrightarrow \infty, i \in \Lambda .
\end{gathered}
$$

By a combination with the continuity of $T_{i}(i \in \Lambda)$, we get

$$
\left\|x_{n}-T_{[n+i]} x_{n}\right\| \leq\left\|x_{n}-x_{n+i}\right\|+\left\|x_{n+i}-T_{[n+i]} x_{n+i}\right\|+\left\|T_{[n+i]} x_{n+i}-T_{[n+i]} x_{n}\right\| \longrightarrow 0 \quad(n \longrightarrow \infty) .
$$


It is clear that for each $l \in \Lambda$, there exists $i \in \Lambda$ such that $l=(n+i) \bmod N$. Consequently,

$$
\lim _{n \rightarrow \infty}\left\|x_{n}-T_{l} x_{n}\right\|=\lim _{n \rightarrow \infty}\left\|x_{n}-T_{[n+i]} x_{n}\right\|=0 .
$$

This completes the proof.

Theorem 3.2. Let the assumptions of Lemma 3.1 hold, and let $T_{i}(i \in \Lambda)$ be continuous. Then, $\left\{x_{n}\right\}$ converges strongly to a common fixed point of $\left\{T_{i}: i \in \Lambda\right\}$ if and only if $\lim _{i n f} \operatorname{in}_{n \rightarrow \infty} d\left(x_{n}, F\right)=0$.

Proof. The necessity is obvious.

Now, we prove the sufficiency. Since $\lim \inf _{n \rightarrow \infty} d\left(x_{n}, F\right)=0$, it follows from Lemma 3.1 that $\lim _{n \rightarrow \infty} d\left(x_{n}, F\right)=0$.

For any $q \in F$, we have

$$
\left\|x_{n}-x_{m}\right\| \leq\left\|x_{n}-q\right\|+\left\|x_{m}-q\right\|
$$

Hence, we get

$$
\left\|x_{n}-x_{m}\right\| \leq \inf _{q \in F}\left\{\left\|x_{n}-q\right\|+\left\|x_{m}-q\right\|\right\}=d\left(x_{n}, F\right)+d\left(x_{m}, F\right) \longrightarrow 0, \quad n \longrightarrow \infty, m \longrightarrow \infty
$$

So, $\left\{x_{n}\right\}$ is a Cauchy sequence in $K$. By the closedness of $K$, we get that the sequence $\left\{x_{n}\right\}$ converges strongly to $x^{*} \in K$. Let a sequence $\left\{q_{n}\right\} \in \operatorname{Fix}\left(T_{i}\right)$, for some $i \in \Lambda$, be such that $\left\{q_{n}\right\}$ converges strongly to $q$. By the continuity of $T_{i}(i \in \Lambda)$, we obtain

$$
\left\|q-T_{i} q\right\| \leq\left\|q-q_{n}\right\|+\left\|q_{n}-T_{i} q\right\|=\left\|q-q_{n}\right\|+\left\|T_{i} q_{n}-T_{i} q\right\| \longrightarrow 0, \quad n \longrightarrow \infty .
$$

Therefore, $q \in F\left(T_{i}\right)$. This implies that $F\left(T_{i}\right)$ is closed. Therefore, $F:=\bigcap_{i=1}^{N} \operatorname{Fix}\left(T_{i}\right)$ is closed. By $\lim _{n \rightarrow \infty} d\left(x_{n}, F\right)=0$, we get $x^{*} \in F$. This completes the proof.

Theorem 3.3. Let the assumptions of Lemma 3.1 hold. Let $T_{i}(i \in \Lambda)$ be continuous and $\left\{T_{i}: i \in \Lambda\right\}$ satisfy condition $(\overline{\mathrm{B}})$. Then, $\left\{x_{n}\right\}$ converges strongly to a common fixed point of $\left\{T_{i}: i \in \Lambda\right\}$.

Proof. Since $\left\{T_{i}: i \in \Lambda\right.$ \} satisfies condition $(\overline{\mathrm{B}})$, and $\lim _{n \rightarrow \infty}\left\|x_{n}-T_{i} x_{n}\right\|=0$ for each $i \in \Lambda$, it follows from the existence of $\lim _{n \rightarrow \infty} d\left(x_{n}, F\right)$ that $\lim _{n \rightarrow \infty} d\left(x_{n}, F\right)=0$. Applying the similar arguments as in the proof of Theorem 3.2, we conclude that $\left\{x_{n}\right\}$ converges strongly to a common fixed point of $\left\{T_{i}: i \in \Lambda\right\}$. This completes the proof.

As a direct consequence of Theorem 3.3, we get the following result.

Corollary 3.4 (see [12, Theorem 3]). Let $H$ be a real Hilbert space, $K$ a nonempty closed convex subset of $H$ satisfying $K+K \subseteq K$, and $T: K \rightarrow K$ continuous hemicontractive mapping which satisfies condition $(\mathrm{A})$. Let $\left\{\alpha_{n}\right\}$ be a real sequence in $(0,1)$ with $\sum_{n=1}^{\infty}\left(1-\alpha_{n}\right)^{2}=+\infty$. For any $x_{0} \in K$, the sequence $\left\{x_{n}\right\}$ is defined by

$$
x_{n}=\alpha_{n} x_{n-1}+\left(1-\alpha_{n}\right) T x_{n}, \quad n \geq 1 .
$$

Then, $\left\{x_{n}\right\}$ converges strongly to a fixed point of $T$. 
Proof. Employing the similar proof method of Lemma 3.1, we obtain by (3.10)

$$
\left\|x_{n}-q\right\| \leq\left\|x_{n-1}-q\right\|^{2}-\left(1-\alpha_{n}\right)^{2}\left\|x_{n-1}-T x_{n}\right\|^{2}
$$

This implies

$$
\sum_{n=1}^{\infty}\left(1-\alpha_{n}\right)^{2}\left\|x_{n-1}-T x_{n}\right\|^{2} \leq\left\|x_{0}-q\right\|^{2}<+\infty
$$

By $\sum_{n=1}^{\infty}\left(1-\alpha_{n}\right)^{2}=+\infty$, we have $\liminf _{n \rightarrow \infty}\left\|x_{n-1}-T x_{n}\right\|=0$. Equation (3.7) implies that $\liminf _{n \rightarrow \infty}\left\|x_{n}-T x_{n}\right\|=0$. Since $T$ satisfies condition (A) and the $\operatorname{limit} \lim _{n \rightarrow \infty} d\left(x_{n}, F\right)$ exists, we get $\lim _{n \rightarrow \infty} d\left(x_{n}, F\right)=0$. The rest of the proof follows now directly from Theorem 3.2. This completes the proof.

Remark 3.5. Theorems 3.2 and 3.3 extend [12, Theorem 3] essentially since the following hold.

(i) Hilbert spaces are extended to uniformly convex Banach spaces.

(ii) The requirement of compactness on domain $D(T)$ on [12, Theorem 3] is dropped.

(iii) A single mapping is replaced by a family of mappings.

(iv) The Mann-type implicit iteration is replaced by the generalized Mann iteration. So the restrictions of $\left\{\alpha_{n}\right\}$ with $\left\{\alpha_{n}\right\} \subset[\delta, 1-\delta]$ for some $\delta \in(0,1)$ are relaxed to $\sum_{n=1}^{\infty}\left(1-\alpha_{n}\right)^{2}=+\infty$. The error term is also considered in the iteration (II).

Moreover, if $K+K \subseteq K$, then $\left\{x_{n}\right\}$ is well defined by (II). Hence, Theorems 3.2 and 3.3 are also answers to the question proposed by Qing [13].

Theorem 3.6. Let $X$ and $K$ be as the assumptions of Lemma 3.1. Let $\left\{T_{i}: i \in \Lambda\right\}: K \rightarrow K$ be strictly pseudocontractive mappings with $\bigcap_{i=1}^{N} \operatorname{Fix}\left(T_{i}\right)$ being nonempty. Let $\left\{a_{n}\right\},\left\{b_{n}\right\},\left\{c_{n}\right\},\left\{u_{n}\right\}$, and $\left\{x_{n}\right\}$ be the sequences in (II) and

(i) $\sum_{n=1}^{\infty} c_{n}<+\infty$,

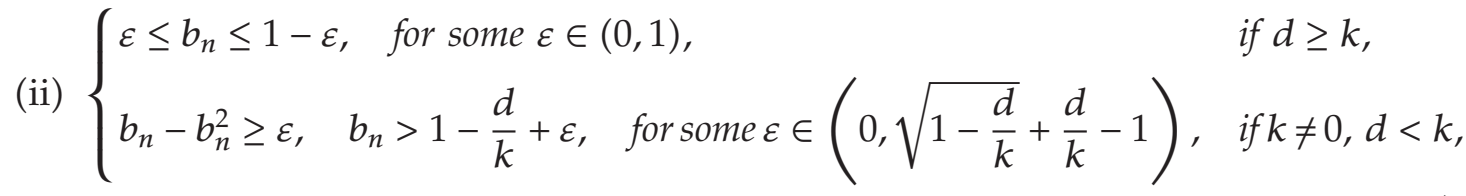

where $d$ is the constant in Remark 2.4. Then,

(1) $\left\{x_{n}\right\}$ converges strongly to a common fixed point of $\left\{T_{i}: i \in \Lambda\right\}$ if and only if $\liminf _{n \rightarrow \infty} d\left(x_{n}, F\right)=0$.

(2) If $\left\{T_{i}: i \in \Lambda\right\}$ satisfies condition $((\overline{\mathrm{B}}))$, then $\left\{x_{n}\right\}$ converges strongly to a common fixed point of $\left\{T_{i}: i \in \Lambda\right\}$. 
Remark 3.7. Theorem 3.6 extends the corresponding result [6, Theorem 3.1].

\section{Acknowledgments}

The authors would like to thank the referees very much for helpful comments and suggestions. The work was supported partly by the National Natural Science Foundation of China, the Specialized Research Fund for the Doctoral Program of Higher Education of China, the NCET04-0572 and Research Fund for the Key Program of the Chinese Academy of Sciences.

\section{References}

[1] F. E. Browder and W. V. Petryshyn, "Construction of fixed points of nonlinear mappings in Hilbert space," Journal of Mathematical Analysis and Applications, vol. 20, no. 2, pp. 197-228, 1967.

[2] L.-C. Ceng, A. Petruşel, and J.-C. Yao, "Implicit iteration scheme with perturbed mapping for common fixed points of a finite family of Lipschitz pseudocontractive mappings," Journal of Mathematical Inequalities, vol. 1, no. 2, pp. 243-258, 2007.

[3] C. E. Chidume and S. A. Mutangadura, "An example on the Mann iteration method for Lipschitz pseudocontractions," Proceedings of the American Mathematical Society, vol. 129, no. 8, pp. 2359-2363, 2001.

[4] C. E. Chidume and B. Ali, "Weak and strong convergence theorems for finite families of asymptotically nonexpansive mappings in Banach spaces," Journal of Mathematical Analysis and Applications, vol. 330, no. 1, pp. 377-387, 2007.

[5] Y.-C. Lin, N.-C. Wong, and J.-C. Yao, "Strong convergence theorems of Ishikawa iteration process with errors for fixed points of Lipschitz continuous mappings in Banach spaces," Taiwanese Journal of Mathematics, vol. 10, no. 2, pp. 543-552, 2006.

[6] G. Marino and H.-K. Xu, "Weak and strong convergence theorems for strict pseudo-contractions in Hilbert spaces," Journal of Mathematical Analysis and Applications, vol. 329, no. 1, pp. 336-346, 2007.

[7] M. O. Osilike and S. C. Aniagbosor, "Weak and strong convergence theorems for fixed points of asymptotically nonexpansive mappings," Mathematical and Computer Modelling, vol. 32, no. 10, pp. 1181-1191, 2000.

[8] B. Prus and R. Smarzewski, "Strongly unique best approximations and centers in uniformly convex spaces," Journal of Mathematical Analysis and Applications, vol. 121, no. 1, pp. 10-21, 1987.

[9] S. Reich, "Weak convergence theorems for nonexpansive mappings in Banach spaces," Journal of Mathematical Analysis and Applications, vol. 67, no. 2, pp. 274-276, 1979.

[10] W. Takahashi, Nonlinear Functional Analysis. Fixed Point Theory and Its Applications, Yokohama Publishers, Yokohama, Japan, 2000.

[11] L.-C. Zeng and J.-C. Yao, "Implicit iteration scheme with perturbed mapping for common fixed points of a finite family of nonexpansive mappings," Nonlinear Analysis: Theory, Methods \& Applications, vol. 64, no. 11, pp. 2507-2515, 2006.

[12] A. Rafiq, "On Mann iteration in Hilbert spaces," Nonlinear Analysis: Theory, Methods \& Applications, vol. 66, no. 10, pp. 2230-2236, 2007.

[13] Y. Qing, "A note on "on Mann iteration in Hilbert spaces, Nonlinear Analysis 66 (2007) 2230-2236"," Nonlinear Analysis: Theory, Methods \& Applications, vol. 68, no. 2, p. 460, 2008. 